\title{
Bestandsestimat og utbreiing av kvitryggspett Dendrocopos leucotos i Noreg
}

\author{
Ingvar Stenberg
}

Stenberg, I. 2004. Status and distribution of the White-backed Woodpecker Dendrocopos leucotos in Norway. - Ornis Norvegica 27: 94-105.

The White-backed Woodpecker, being classified as a vulnerable species in Norway, has declined dramatically in western Europe during the last decades. The primary reason is that forestry has removed dead deciduous trees with insect larvae, which constitutes its main food. At present, the only viable population in western Europe is found along the southern and western coast of southern Norway. Our responsibilities for a proper management of the species makes it important to know its status and distribution well. This is the main reason for the present paper, where the White-backed Woodpeckers historical and present distribution is described for each county. During the main survey of the species in Norway i.e. after 1985, it is reported during breeding from all counties in southern Norway except Hedmark, but only in autumn in northern Norway. The species is very scarce in the eastern part of the country, especially in the counties of Hedmark and Østfold, where only one nest is found after 1960 . Hundred years ago it was relatively common in places in this area. Further west, in Oppland, its present distribution is very scattered, although it still may be breeding. During the last decades the decline of the species is best documented in the counties along the Oslofjord: Oslo-Akershus and Vestfold. Deciduous forest along watercourses and in hillsides were important habitats before most of these areas were clearfelled and planted with conifers. This also applies to the coastal areas of Telemark, but the species has fared better in the inner parts of this county, where today the only regular breeding population in eastern Norway is found. Although it is also a regular breeder in Aust-Agder, its distribution is somewhat scattered, in contrast to the very even occurence in most of Vest-Agder. Combined with favourable climatic condition, the steep terrain along fjords makes the forests along the western coast north to Trøndelag an optimal habitat for the species. The topography makes forestry avtivities difficult in many places, and the White-backed Woodpecker has a strong foothold, being somewhere the most common woodpecker species in the four counties of western Norway. It also breeds regularly in Trøndelag south of Trondheimsfjorden, but there are no evidences for breeding in northern Norway. Based on the present occurrence and densities of breeding pairs, the Norwegian population is estimated to about 1800 pairs.

Ingvar Stenberg, N-6640 Kvanne.E-post: Ingvar.Stenberg@c2i.net

\section{INNLEIING}

Blant dei europeiske hakkespettane er kvitryggspetten av dei mest spesialiserte i habitat- og næringsvalg, og også av dei mest sårbare for endringar i skogstrukturen (Scherzinger 1982, Angelstam \& Mikusinski 1994). Hovednæringa er ved- og barklevande insektlarver i morkne lauvtre (Aulén 1988, Hogstad \& Stenberg 1997). Reduksjon av leveområda hans har i løpet av siste århundret medført drastisk bestandsnedgang i sentral-Europa, der han somme stader er utdøydd (Glutz \& Bauer 1980, Cramp 1985). Kvitryggspetten er i dag den sjeldnaste hakkespetten i Europa, og vest for tidlegare Sovjetunionen finst han hovudsakleg som isolerte bestandar i Alpane, Apenniane og Pyrenéane (Fernandez \& Azkona 1996, Spiridinov \& Virkkala 1997). Etter tidlegare å ha vore vidt utbredt i Fennoskandia, har bestanden gått dramatisk tilbake siste del av 1900-talet (Aulén 1986, Tiainen 1990), sannsynlegvis 
pga. endringar i skogsdrift og fragmentering av habitatet (Aulén 1988, Virkkala et al. 1993).

Kvitryggspetten er klassifisert som sårbar på den norske raudlista over truga artar (Direktoratet for naturforvaltning 1999), og er rekna som direkte truga både i Sverige (færre enn 10 par; Aulén et al. 1992, Stighäll et al. 2004) og Finland (ca 50 bebodde revir; Lehtiniemi 2001).

Før Håland \& Toft (1983) og Håland \& Ugelvik (1987) si oppsummering av eksisterande kunnskap var svært lite publisert om artens utbreiing i Noreg. På denne tida starta eit meir målretta kartleggingsarbeid, som med varierande intensitet har fortsatt fram til no. A talfesta hekkebestanden krev stor feltinnsats, fordi arten har eit skjult levevis og er vanskeleg å oppdaga. Denne artikkelen er i stor grad basert på NOF Rapport nr 6-2001 (Stenberg 2001).

\section{METODAR OG MATERIALE}

Datagrunnlaget til artikkelen er skaffa frå litteraturstudiar og opprop utsendt til NOFs fylkesog lokallag, LRSK (Den Lokale Rapport- og Sjeldenhetskomitéen) samt sentrale personar i kartleggingsarbeidet. Data frå Fylkesmannens viltkartverk er inkludert. Ei viktig kjelde fram til 1989 er Atlas-prosjektet over norske hekkefuglar (Gjershaug et al. 1994). Når ikkje anna er opplyst, stammar registreringane frå februar-juli. Dette er kvitryggspettens viktigaste tid for revirhevding og hekking.

\section{RESULTAT}

\section{Utbreiing}

\section{$\underline{\text { Austlandet }}$}

\section{Naturgrunnlaget}

Barskogen dominerer Austlandet, men lauvskogsarealet aukar vesentleg frå Hedmark i aust (ca 9\%) til Vestfold (ca 29\%; Tomter 1994). Rik lauvskog er mest utbredt i fylka kring
Oslofjorden, der lauvblandingsskogar stadvis utgjer eit stabilt og naturleg klimakssamfunn, særleg i bratte skrentar der grana vanskeleg får fotfeste (Heggland 2000, jf. Bleckert \& Petterson 1997). Dette har tidlegare vore viktige habitat for kvitryggspetten.

\section{Bestanden}

Historiske kjelder tyder på at kvitryggspettens tilbakegang på Austlandet går over hundre år tilbake i tid. Først på 1800-talet var han omtala som vidt utbredt og lokalt hyppig, trass $i$ at han generelt var fåtalig. Som for dei fleste hakkespettane minka bestanden markert på 1800-talet. Truleg skuldast dette omfattande hogst, særleg av osp til fyrstikkproduksjon. Omkring 1900 fanst arten enno spredt og somme stader relativt vanleg $\mathrm{i}$ landsdelen (Collett 1864, 1921). Utviklinga fram til omkring 1970 er dårleg dokumentert, men var truleg negativ, sidan dette var første spettearten som forsvann ved intensivering av skogsdrifta (Hågvar 1991). Auka tal på hekkefunn i 1970åra, særleg i Oslo Vestmark (Gjerde et al. 1992), kan skuldast grundigare leiting. Dette kan og gjenspegla ein bestandstopp, tilsvarande som hjå tretåspetten (jf. Hogstad 1970), pga. kraftige hauststormar som i 1969 skapte mykje daud ved i Sør-Skandinavia og dermed godt mattilbod pga. insektangrep. Seinare år har uttak av dødt trevirke og minka areal lauvrik gammelskog redusert næringstilbodet i landsdelen, der kvitryggspetten i dag finst svært få stader (jfr. Tabell 1). Bestandskartlegginga på Austlandet var mest målretta sist på 1980-talet (Rinden 1991), og har i seinare år vore konsentrert om Telemark (Heggland 2004a).

I Hedmark har kvitryggspetten gått tydeleg tilbake siste århundret, og ingenting tyder på hekking i dag. Først på 1900-talet var han utbredt $\mathrm{i}$ søndre del, der han hekka spredt i Hamar stift og var alminneleg på Hedemarken (Collett 1921). Han forsvann i 1940-åra etter utstrakt vedhogst i hagemarkene (Johan Kielland-Lund pers. obs), og er rapportert berre éin gong seinare frå Hedemarken (LRSK). I Grue kommune på Finnskogane var arten omtala som alminneleg på 
Tabell 1. Fordeling av observasjonar i hekketida (april-juni) og hekkefunn i 1971-80, 1981-90 og 1991-2000 i fylka på Austlandet. Fleire observasjonar på same lokalitet same år er oppført som ein observasjon.

\begin{tabular}{|c|c|c|c|c|c|c|c|}
\hline & \multicolumn{2}{|c|}{ 1971-1980 } & \multicolumn{2}{|c|}{ 1981-1990 } & \multicolumn{2}{|c|}{ 1991-2000 } & \multirow[b]{2}{*}{ Kjelde } \\
\hline & Obs & Hekkef. & Obs & Hekkef. & Obs & Hekkef. & \\
\hline Hedmark & 2 & 0 & 0 & 0 & 0 & 0 & LRSK \\
\hline Oppland & 8 & 3 & 12 & 0 & 0 & 1 & LRSK, (1) \\
\hline$\emptyset_{\text {stfold }}$ & 0 & 1 & 1 & 0 & 1 & 0 & LRSK, (1) \\
\hline Akershus/Oslo & 4 & 14 & 3 & 5 & 2 & 0 & LRSK, (1) \\
\hline Vestfold & 9 & 11 & 10 & 13 & 10 & 1 & LRSK, A.Heggland, (1) \\
\hline Buskerud & 9 & 0 & 6 & 2 & 3 & 1 & LRSK, (1), (2) \\
\hline Telemark & 8 & 6 & 13 & 4 & 23 & 10 & R.Solvang, E.Edvardsen \\
\hline \multicolumn{8}{|c|}{ (1)=Rinden 1991 og i brev, (2)=Gjerde et al 1992} \\
\hline
\end{tabular}

1930-talet, men er ikkje sett etter 1974 (Sollien et al.1976, LRSK).Av totalt berre sju observasjonar frå fylket etter 1970, er einast éin frå hekketida (Strøm et al. 1998).

Einaste reirfunn etter 1990 på indre Austlandet er frå Midtre Gudbrandsdalen i Oppland, der arten sist i 1980-åra hadde 3-4 territorier i bratte dalsider med lauvskog (Opheim \& Høitomt 1990, Opheim et al. 1998, LRSK). På same tid var han kjent frå to andre hekkelokalitetar i fylket: Vangsmjøsa i Valdres og Dokkadeltaet. Gjentatte observasjonar ved Vangsmjøsa, både i 1980-åra og etter 2000 (Bjørn Harald Larsen, Thor Østbye pers. obs), tyder på regelmessig hekking, og den relativt korte avstanden til Vestlandsbestanden kan tenkast vera fordelaktig for rekrutteringa. Desse liene er blant dei mest lauvrike i Oppland. I sør er lauvskogen vesentleg erstatta med gran, og kvitryggspetten er ikkje rapportert.

Frå Østfold er einast eitt hekkefunn kjent sidan først på 1900-talet (Collett 1921); ved Lundsneset nær riksgrensa i sør i 1976 (Jørn Bøhmer-Olsen pers. obs). I 1996 hekka han eit par mil herfrå på svensk side, der han framleis fanst i 2001, få km frå det norske reirfunnet (Olsson 1998, Kristoffer Stighäll pers. komm.). Dette gir håp om ein liten bestand i skogane ved riksgrensa, som er prega av raviner med stadvis mykje 96 daud lauvskog. Somme stader i Østfold var han relativt vanleg i dette habitatet for nokre tiår sidan (Wergeland Krog 1997). I vår tid er han ytterst sparsam, og vart ikkje påvist i hekketida ved Andersens (1988) omfattande inventering av aktuelle lauvskogsbiotopar i 1987-88. Berre eitt av fem rapporterte funn frå fylket etter 1990 er frå hekketida (Frølandshagen 1996, LRSK).

I Oslo og Akershus har hogst og auka habitatfragmentering svekka bestanden, og rekrutteringa synest i dag så dårleg at jamvel verna, intakte hekkebiotopar står tomme (Rinden 1991, Per Henry Gylseth pers. obs). Ved sidan av nabofylket Vestfold er det her bestandsnedgangen er best dokumentert i vårt land. Siste reirfunn på dei sju kjente hekkelokalitetane frå 1970-åra i Vestmarka var gjort i 1981, der berre eitt av tre funn i ettertid er frå hekketida (Rinden 1991, LRSK, Rune Aanderaa pers. obs). I 1980-åra hekka fuglen regulært eit par mil lengre aust, i gråorskogane ved Øyeren-deltaet, men er ikkje rapportert herfrå etter 1991 (Knut Eie, Trond Aspelund pers. obs). Rinden (1988) vurderer sjansane for arten best i dei lauvrike delane av den kuperte $\emptyset$ stmarka, som var blant dei få områda i Oslo og Akershus med regelmessige observasjonar i 1980-åra. Lengst i søraust, ved svenskegrensa, var arten årviss om hausten $\mathrm{i}$ 1950-60-åra, da det enno var vesentleg med 
osp og bjørk i skogane. Etter at ospeholta vart erstatta med planta gran, forsvann fuglen på 1970-talet (Johan Kielland-Lund pers. obs).

Sentralt i Vestfold fanst tidlegare eit kjerneområde for kvitryggspett med kanskje beste bestanden på Austlandet. Næringsrikt jordsmonn og varmt sommarklima gir frodige naturtilhøve, og lauvskogen har her si største utbreiing på Austlandet (Tomter 1994, Moen 1998). Lenge prega naturskogen store delar av fylket takk vera mykje tungdrive skogsterreng. Utstrakt hogst, særleg på 1970-talet, endra dette bildet vesentleg. Dette reduserte den tette bestanden på minst 20 (-50) par til ein restbestand i løpet av 20-30 år. Sist i 1980-åra var ei rekkje tradisjonelle hekkeområde forlatt, og årviss inventering over $60-70 \mathrm{~km}^{2}$ har seinare resultert i berre eitt reirfunn. Arten forekjem svært ustabilt på dei ca 3-5 eigna hekkeområda, og siste rapporterte funn i hekketida er frå 2000. Spredte funn i nord kan tyda på kontakt med bestanden i søndre del av Buskerud (Heggland 1991, 2000 og i brev; Frode Omland pers. komm.; LRSK).

I Buskerud er kjent berre tre reirfunn og ti observasjonar i hekketida etter 1980 (Tabell 1). Bestandsutviklinga er dårleg dokumentert, men tilbakegangen må ha vore markert etter 1950-åra, da arten stadvis i sør var omtalt som den vanlegaste spettearten (Fylkesmannen \& Fylkeskommunen i Buskerud 1996). I ravinedalar med lauvskog fanst fuglen regelmessig her fram til 1990, men er ikkje kjent i ettertid, da hogst har redusert biotopane. Lengst sør i fylket finst høvelege biotopar i osp- og edellauvskogar, der han sidan 1990 er kjent frå 3-4 lokalitetar i hekketida (Jensen 1996, LRSK). Gjentatte observasjonar øvst i Hallingdal, nær grensa mot Vestlandet, kan tyde på at han er mest regulær i dette området (T. Breiehagen, K. Plischwski pers. komm.).

I Telemark er arten svært sjeldan, men intensivert kartlegging sidan sist på 1990-talet har auka tal på observasjonar. Etter tilbakegang pga. hogst av noko av dei beste habitata nær kysten i 1970- åra, synest bestanden i dag sterkast i indre strok, som har store areal lauvrik skog både langs vassdraga og i brattlier. Han er kjent frå ca 30 lokalitetar i fylket, men kartlegginga er på langt nær fullstendig (Edvardsen et al. 1999, Heggland 2000, 2004a).

\section{$\underline{\text { Sør- og Vestlandet }}$}

\section{Naturgrunnlaget}

Lauvskogsandelen aukar frå Agderfylka på Sørlandet (23\%) til Vestlandet (46\%; Tomter 1994). Eit særtrekk for Sørlandet er dei omfattande eikeskogane. Skoglandskapet på Sørog Vestlandet har gjennom århundra vore sterkt menneskepåvirka pga. husdyrbeite, slått og vedhogst. I Hordaland var ytre og midtre strok nærmast snauhogde ved århundreskiftet. Utmarka har no pånytt vokse att, først og fremst med lauvskog, og skogarealet i dette fylket er nær fordobla etter krigen. Lang vekstsesong og mykje nedbør i kyststroka gir rekordarta veksttilhøve (Moe 1991, Fylkesmannen i Hordaland 1993). Tilgangen på daud ved er jamnt over god, både som resultat av attgroing og sjølvtynning av yngre skog og fordi det bratte terrenget mange stader begrensar skogsdrifta. Saman med det vintermilde klimaet gir dette kvitryggspetten gode vilkår.

\section{Bestanden}

På Sørlandet var kvitryggspetten for hundre år sidan omtala som relativt alminneleg hekkefugl (Collett 1921). På Vestlandet var status for dei fleste fugleartane svært dårleg kjent før 1970 (Haftorn 1994), og dei få rapportane om arten (jfr. Håland \& Toft 1983) gjenspeglar nok i stor grad manglande unders $\emptyset$ kingar.

I Aust-Agder har kvitryggspetten hovud-utbreiinga i kystnære lauvskogar med vesentleg innslag av eik o.a. edle treslag. I midtre delar hekkar han helst i tilknytning til gammal ospeskog, og reirfunn er gjort 7-8 mil frå kysten. Kunnskapen om bestanden er svak, men han er blant dei sjeldnaste hakkespettane, og viser ei 
nokså vid men noko flekkvis utbreiing (Bengtson 1993; Lislevand 1994, 2000; Heggland 2004b).

Vest-Agder har eit svært kollete og småkupert landskap med skiftande vegetasjon. Det berglendte terrenget begrensar skogsdrifta, og betyr god tilgang på daud ved. Kvitryggspetten er utbredt samanhengande i den vintermilde kystsona, og hekkar særleg tett i dei mest lauvrike komunane i vest (t.d. Flekkefjord). I austlege og indre delar er bestanden meir glissen, men han er registrert revirhevdande opp til 550 moh. (Geir og Svein Grimsby, Per Kristian Stokke pers. obs).

Like vest for fylkesgrensa til Rogaland blir landskapet meir åpent og skogfattig, og i søndre del av fylket forekjem kvitryggspetten spredt og fåtalig. Habitat-tilhøva betrar seg vesentleg nordover frå fjord- og dalstroka i Ryfylke, med sine ulendte lier og gammal, grovvaksen blandingsskog av furu, bjørk og osp. Her er fuglen jamnt utbredt og er ved sidan av gråspetten vanlegaste hakkespetten (Toralf Tysse pers. obs).

I Hordaland og Sogn og Fjordane er arten vidt utbredt i dei lauvrike liene og registrert i dei fleste kommunane. Trass $i$ at han er blant dei vanlegaste hakkespettane, forekjem han spredt, og er t.d. karakterisert som sjeldan i Voss kommune (Chapman 1987). I kystregionen synest bestanden meir glissen enn innover fjordstroka, men eit særtrekk for Vestlandsbestanden er regulær hekking i oseanisk furuskog, der daud furu er eit viktig næringstre. Kanskje kombinasjonen av fuktigare klima og høgare bonitet enn furuskogane i innlandet er gunstig for insektslivet og følgeleg for fuglens næringsvilkår (Håland 1985, Håland \& Ugelvik 1987, 1992, Stenberg 2003). Truleg har bestanden auka noko i eit 20årsperspektiv $\mathrm{i}$ takt med tilgroinga av skog på gammal kulturmark (Håvard Bjordal, Johannes Anonby pers. obs).

Møre og Romsdal er frå eldre tid kjent som viktig for arten. Collett (1921) oppgir at bestanden i vårt land var mest talrik i Nordmøre og Romsdal. At dette var vanlegaste hakkespetten i Surnadal, stemmer med situasjonen i dag, og gjeld også på fylkesplan. Landskapet er oppdelt av forgreina fjordarmar, og fuglen likar seg i dei bratte liene med lauvskog (Fig. 1). Lengst nord, der granskogen finst naturleg og er mest dominerande, er bestanden tynnare.

\section{Trøndelag}

\section{Naturgrunnlaget}

Andelen lauvskog minkar nord for den sørlege fylkesgrensa av Trøndelag, og grana er mange stader dominerande. Dette påverkar høgst sannsynleg levevilkåra for kvitryggspetten. Artens status i landsdelen var lite kjent før NOF sist i 1990-åra starta eit kartleggingsprosjekt (Myklebust 1996, Edvardsen et al. 1997, Solbakken et al. 1999, 2001a og b).

\section{Bestanden}

I Sør-Trøndelag avvik utbreiingsmønstret frå Møre og Romsdal, ettersom bestanden synest samanhengande berre i kystnære fjordstrøk. Forekomst i midtre og indre strøk er truleg avhengig av rekruttering frå dalføra som går vestover til Nordmøre. Han er påvist territoriell opptil ca 10 mil frå kysten.

At kvitryggspetten ikkje er nemnt i Kutscheras (1997) hakkspett-kartlegging i kyststroka lengst nord i Nord-Trøndelag, tyder ikkje på regulær hekking så langt nord. På 1990-talet er arten registrert berre éin gong i hekketida nord for Trondheimsfjorden, og siste kjente hekking er frå 1974, nær riksgrensa mot Sverige.

\section{Nord-Noreg}

Fuglen er ikkje rapportert i hekketida, men etter 1980 er han påvist tre gonger i Nordland og éin gong i Troms (LRSK). Einaste målretta inventering i hekketida var gjort i dei rikaste lauvskogsliene på Helgelandskysten i 2004. Bortsett frå kvitryggspetten vart alle seks norske 
hakkespettar påvist, truleg hekkande (Gaarder et al. 2004).

\section{Tetthet og storleik av bestanden}

\section{Austlandet}

Truleg er det einast Telemark som har ein fast hekkebestand, som er antatt å telja maksimum 50-60 par (Heggland 2004a). Totalbestanden for Austlandet er neppe vesentleg høgare.

\section{Sørlandet}

I Aust-Agder tyder kartlegging på 1990-talet på ca 50-70 par (Terje Lislevand pers. komm.). Fuglen er jamnare utbredt i Vest-Agder, og takseringar på 1990-talet av tilfeldig utvalte ruter på $5 \times 5 \mathrm{~km}$ $(n=19)$ viste ei gjennomsnittleg minimumstetthet på 0,14 par pr $\mathrm{km}^{2}$ skogkledd areal. Samanhalde med totalt skogareal gir dette ein minstebestand i fylket på ca 430 par (Stokke 1993 og upublisert, Geir og Svein Grimsby pers. komm).

\section{Vestlandet}

Frå 1990-åra finst tetthetsverdiar for Møre og Romsdal (seks undersøkte område; totalt ca 700 $\mathrm{km}^{2}$ ) og Hordaland (to område; totalt ca 180 $\mathrm{km}^{2}$ ). I furudominert skog i Møre og Romsdal var gjennomsnittleg tetthet $0,06 \mathrm{par} / \mathrm{km}^{2}$ (Stenberg \& Hogstad 1992). Bestandstal frå oseanisk furuskog i Hordaland (Håland \& Ugelvik 1992) kan tyde på uvesentleg høgare tetthet. Lauvdominert skog hadde gjennomsnittstetthet på $0,16 \mathrm{par} / \mathrm{km}^{2}$ i Møre og Romsdal (Stenberg \& Hogstad 1992). Ekstremt tett synest bestanden i indre fjordstrøk av Hordaland, med 0,50 par pr km² (Voie 2001). Store mengder daud ved, brekt ned av snøras og fonnvind med enorm kraft, gir truleg ekstra gode næringsvilkår her. Desse lange, bratte lauvskogsliene er av dei mest rasutsatte i landet (Fig. 2). Ved å samanhalde tetthet i Møre og Romsdal med skogarealet på Vestlandet kan totalbestanden i landsdelen estimerast til ca 1.200 par.

\section{Trøndelag}

Kartlegging på 1990-talet gir grunn til å anta ein hekkebestand på omkring 50 par, der storparten finst i Sør-Trøndelag (Solbakken 1999).
Dette inneber at av den estimerte norske totalbestanden på 1.780 hekkande par finst ca $90 \% \mathrm{i}$ kystskogane frå Vest-Agder til Møre og Romsdal (Fig. 3, Tabell 2).

\section{DISKUSJON}

Kvitryggspetten er standfugl, og dei vaksne er knytta til hekkereviret året rundt, normalt heile livstida (Stenberg \& Carlson 1998). I periodar kan han opptre som streif- og invasjonsfugl. I nyare tid er dette best dokumentert i Finland, der han var meir talrik enn vanleg både i 1987 og 1993, og hekkebestanden har seinare synt ein viss framgang (Virkkala et al. 1993, Carlson 1999, Lehtiniemi 2001). Hos oss finst døme på forbigåande oppgang utanfor hekketida frå indre Austlandet (Sollien et al. 1976). I denne landsdelen synest arten i vår tid å visa seg oftast haust og vinter. Mest sannsynleg er dette ungfugl på utvandring, t.d. frå hekkeområda på Sør- og Vestlandet, eller austfrå i Europa. Lengste kjente forflytning av ungfugl i vårt land er 55 km (Stenberg 2000), i Finland $120 \mathrm{~km}$ (Virkkala et al. 1993). At ungfuglar kan streifa atskillig lengre første hausten, viser ein ung hannfugl frå Sverige som flytta over $500 \mathrm{~km}$ (Arvidsson 2000).

Sjølv om kvantitative data manglar, tyder Colletts (1921) beskriving på at det har skjedd regionale endringar av den norske bestanden dei siste hundreåra. Dette er mest markert på Austlandet, der tilbakegangen var tydeleg alt på 1800-talet, og han er i dag borte frå område der han var regelmessig tidleg på 1900-talet. Årsaka er høgst sannsynleg reduksjon av eigna lauvhabitat pga. intensivert skogsdrift (Collett 1921, Gjerde et al . 1992). Arealet lauvdominert skog i landsdelen har minka med ca 20\% berre sidan 1960-talet (Gjerde et al. 1992). I historisk perspektiv har dessutan skogbrannfrekvensen påverka lauvinnslaget, og i barskogsområda er dette rekna for å vera viktigaste forma for skogleg forynging i eldre tid. Meir effektiv slokking utover 1800-talet reduserte arealet av brannflater og dermed tilveksten av osp og bjørk etter brann (Aulén 1986, Gjerde et al. 1992). Dette har utvilsamt 


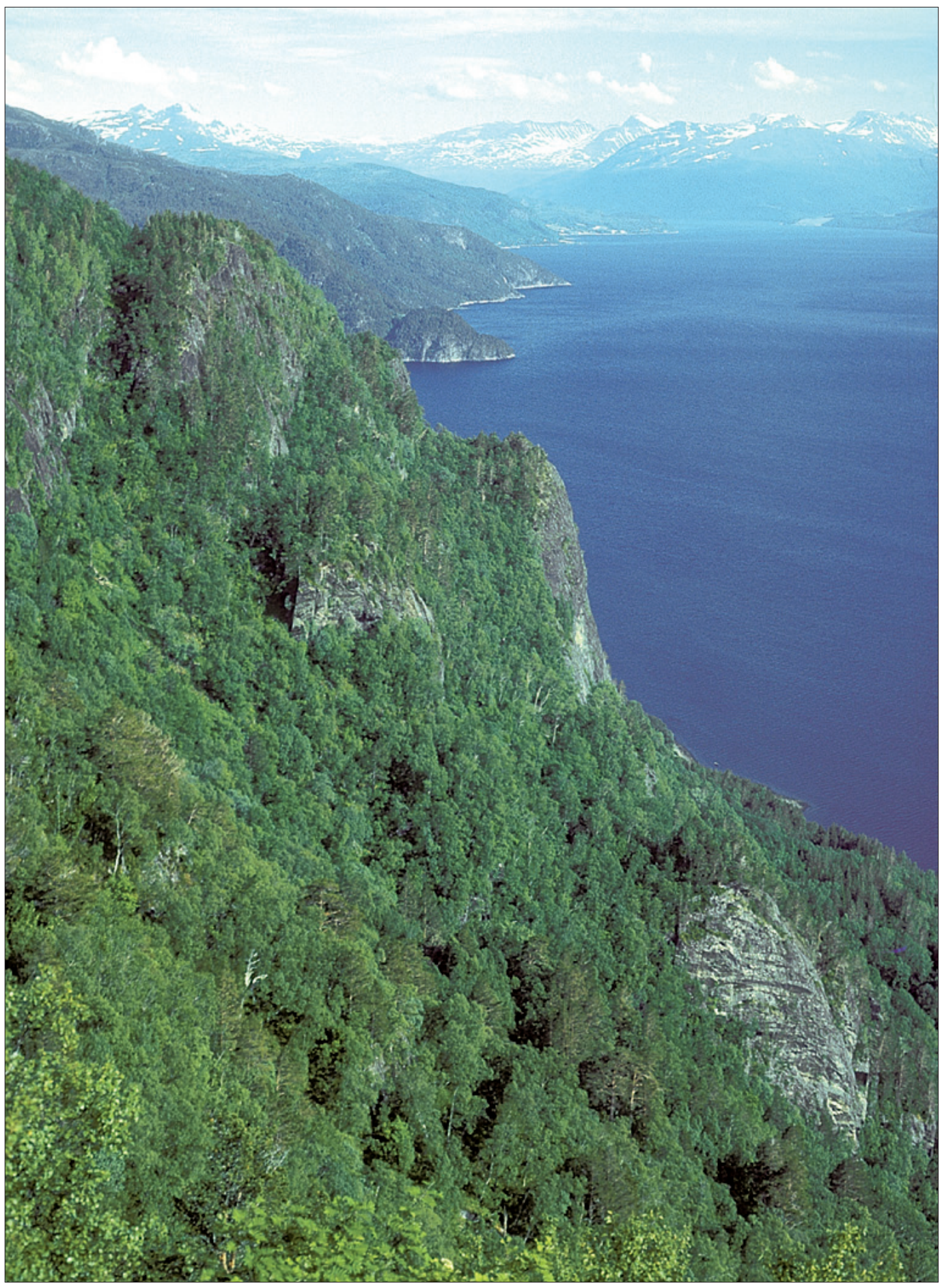

Figur 1. Typisk hekkehabitat for kvitryggspett i fjordstroka på Nordmøre. Foto: Ingvar Stenberg. 


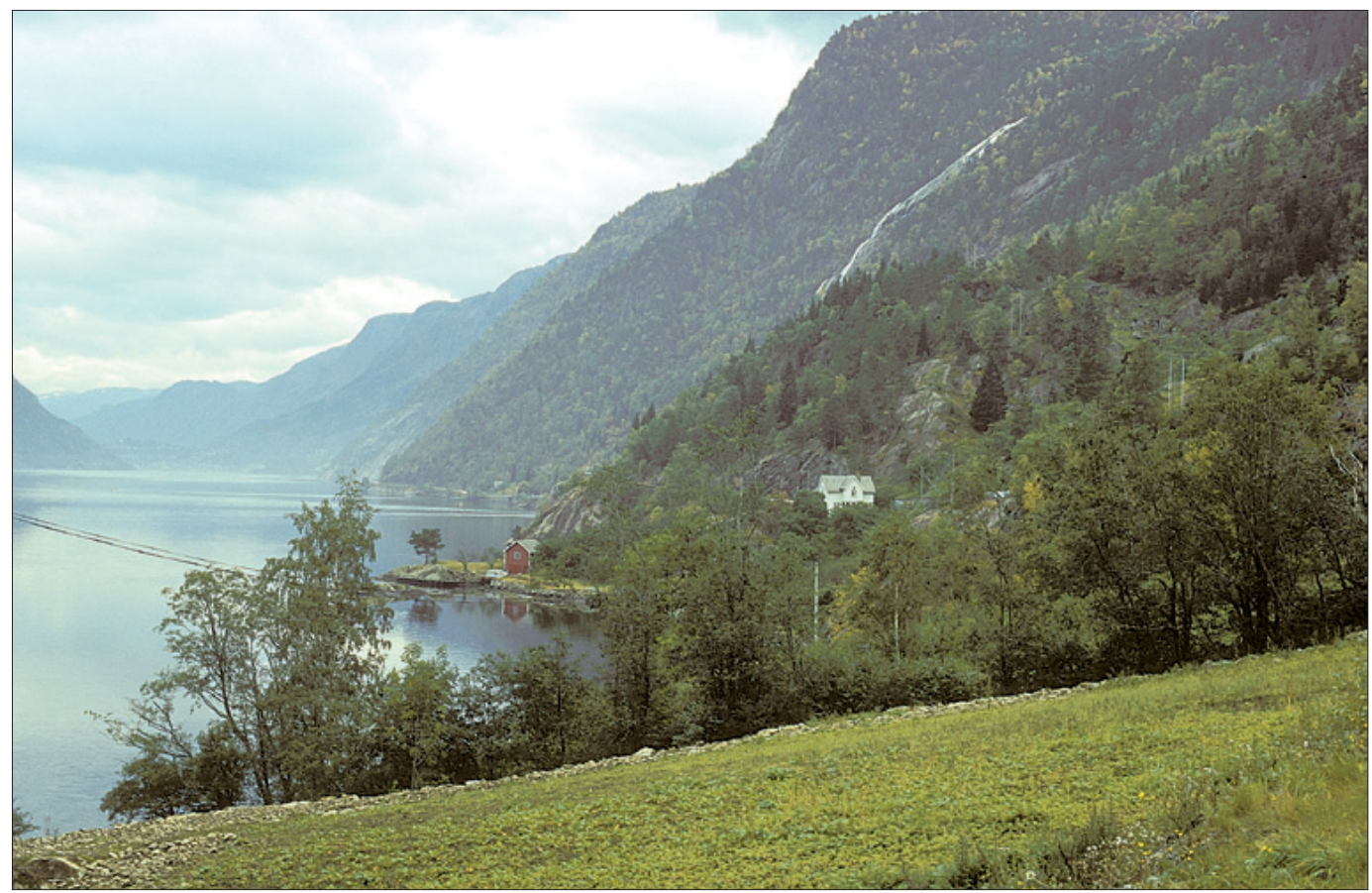

Figur 2. I dei bratte lauvskogsliene langs Sørfjorden i Indre Hardanger har kvitryggspetten kanskje si høgaste tetthet i Fennoskandia. Foto: Ingvar Stenberg.

påverka habitatvilkåra for kvitryggspetten på lang sikt, men konkret kunnskap om effekten på bestanden manglar.

Avskoging pga. hard hogst slik som beskrive frå somme strok av Vestlandet i tidlegare århundre (Fylkesmannen i Hordaland 1993), tyder på dårlegare habitatvilkår enn i dag. I tråd med dette gir Collett (1921) inntrykk av at Vestlands-bestanden i alle fall somme stader var meir fåtalig enn på Austlandet. At arten lengst nord på Vestlandet synest ha hatt betre fotfeste frå gammalt av, kan kanskje skuldast mindre press på skogressursane? Historiske kjelder gir sjølvsagt ikkje fullgode svar korkje på bestandsforhold eller habitatvilkår, men avskoginga var neppe fullstendig nokon stad (jfr. Moe 1991). Trass $\mathrm{i}$ at presset på skogressursane var hardt, stod truleg større areal mindre lagleg til for hogst før skogbruket vart mekanisert. Dette kan ha medvirka til meir lokal og/eller regional variasjon i skogbildet. Også i nyare tid, etter 1950, kan det tenkast at Vestlands-bestanden har gått fram i takt med auka tilvekst av lauvskog pga. redusert vedhogst og skogbeite (Gjerde 1993). Dette kan vera $\mathrm{i}$ ferd med å endra seg i dag med auka interesse for vedfyring.

Parallelt med tilbakegangen på Austlandet kan kvitryggspetten altså ha ekspandert på Vestlandet på 1900-talet. Kanskje dette kan gi perspektiv på den framtidige utbreiinga? Kan det tenkast at dei mest lauvrike delane av Austlandet, vest for Oslofjorden, kan utviklast i gunstig retning og på nytt bli kolonisert? Lauvoppslaget på dei relativt store areal hogstflater som ikkje er tilplanta med bartre, kan gi håp om framtidig betring av habitatsituasjonen (Heggland 2000). Klåre forvaltningsplanar krevst for å sikra at denne skogen skal nå høveleg alder og bli eigna habitat. Hovudproblemet for arten over det meste av Austlandet synest vera at lauvtrea forekjem for spredt til å kunne utnyttast effektivt ved fødes $\varnothing \mathrm{k}$ (Gjerde et al. 1992). 


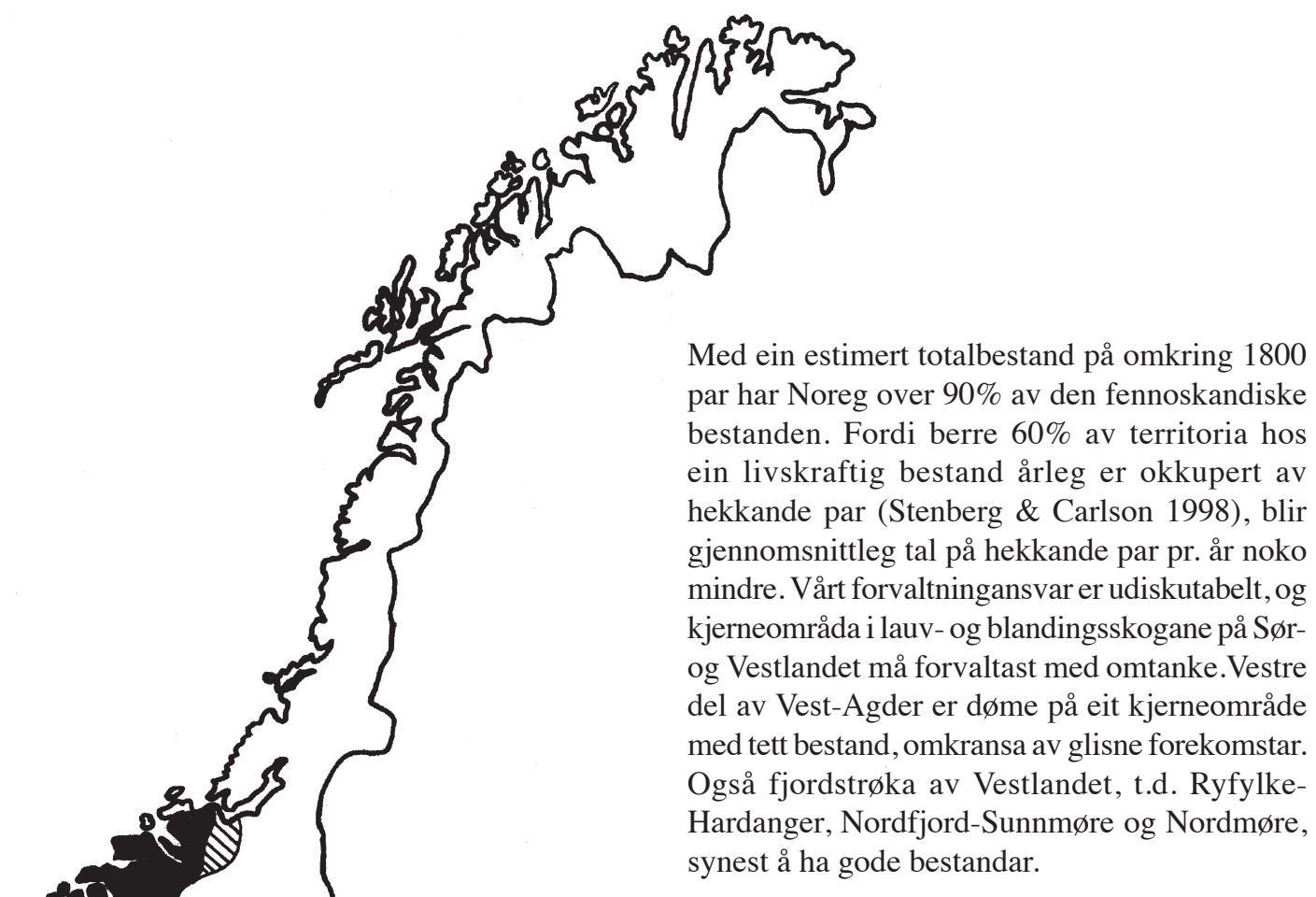

Kor sårbar arten er for habitatendringar er best dokumentert hos den finske bestanden, som minka frå anslagsvis 1000 par på 1950-talet til 30-50 par i dag, parallelt med halvering av lauvskogsarealet (Virkkala et al. 1993, Lehtiniemi 2001). Andelen eigna habitat i det finske landskapet er i dag mindre enn det berekna minimum på ca $15 \%$ som ein bestand treng for å halda seg levedyktig. Framtida for bestanden avheng truleg av immigrasjon frå aust (Carlson 1999).

Figur 3. Utbreiingsbilde av kvitryggspett $i$ Dendrocopos leucotos $i$ Noreg omkring 2004. Svart: God bestand; Skravert: Glissen men fast bestand; Prikka: ustabil/usikker bestand.

Tabell 2. Estimert hekkebestand av kvitryggspett Dendrocopos leucotos $i$ Noreg $i 2004$.

\begin{tabular}{lr} 
Austlandet & $50 \mathrm{par}$ \\
Aust-Agder & $50 \mathrm{par}$ \\
Vest-Agder & $430 \mathrm{par}$ \\
Vestlandet & $1.200 \mathrm{par}$ \\
\hline Trøndelag & $50 \mathrm{par}$
\end{tabular}

Prognosane for fuglen synest atskillig lysare på norske Sør- og Vestlandet, der lauvskogsarealet har vore aukande pga. ein attgroingsfase. Ei målretta forvaltning, med kartlegging og trygging av gode biotopar, er viktig for å sikra ei mest muleg samanhengande utbreiing. Kvitryggspetten reagerer eintydig negativt på granplanting (Gjerde 1993), noko som truleg er største trugsmålet i denne landsdelen. Omfattande lauvskogsdrift kan og vera ein risiko, særleg hogst av osp, som er viktigaste reirtreet (Stenberg 1996). Forutsetningane for å ta vare på arten bør likevel 
vera gode i landsdelen, der kombinasjonen av topografi og eigedomsstruktur begrensar storskala-drift. Dette er truleg to avgjerande faktorar som sikrar eit nettverk av restbiotopar langt betre enn på Austlandet (og resten av Fennoskandia). Samanbrotet i bestanden her skuldast høgst sannsynleg gradvis fragmentering habitatet, der eigna lauvskogsbiotopar med daud ved etterkvart har vorte for små og isolerte. Arealet eldre lauvdominert skog på indre/austre Austlandet må nær tredoblast, frå ca 5\% i dag og over terskelverdien som ein bestand treng for å overleva på lang sikt. Arten har noko lysare utsikter i Vestfold/Telemark, der dette habitatet utgjer $12 \%$ av skogarealet (jfr. Tomter 1994). Heggland (2004a) peikar på at Telemark, som einaste Austlandsfylke med fast hekkebestand i dag, kan ha ein framtidig nøkkelrolle som muleg springbrett for rekolonisering austover mot dagens meir lauvfattige skogar.

\section{SAMANDRAG}

\section{Bestandestimat og utbreiing av kvitryggspett i Noreg.}

Kartlegginga av kvitryggspett i Noreg har vore mest målretta etter 1985. I perioden 1990-2003 var arten registrert i hekketida i alle fylka i Sør-Noreg bortsett frå Hedmark, medan begge funna i Nord-Noreg var gjort om hausten. Over store delar av Austlandet er bestanden i dag forsvinnande liten, og einaste hekkefunn på indre Austlandet i dette tidsrommet er frå Oppland. I Hedmark er det ingen teikn til hekking i nyare tid, trass $i$ at han var stadvis alminneleg første del av 1900-talet. Tilbakegangen synest best dokumentert i Oslo-Akershus og Vestfold, der han i dag opptrer svært spredt og fåtalig, men enkelte par hekkar truleg framleis. Telemark er einaste Austlandsfylket med ein hekkebestand av betydning. Mot vest aukar bestanden frå å vera glissen og spredt i Aust-Agder til den særleg tette forekomsten i vestre del av Vest-Agder. Vidare synest han relativt jamnt utbredt i fjord- og dal- stroka på Vestlandet nord til Nordmøre, lokalt med rekordarta tethet. Bestanden blir tynnare $\mathrm{i}$ Trøndelag, og i Nord-Trøndelag er berre eitt eldre reirfunn kjent. Foreliggande data tyder på at den norske hekkebestanden er på ca 1800 par.

\section{TAKK}

Utan hjelp frå lokalkjente ornitologar kunne ikkje dette arbeidet vore gjennomført, og eg ønsker å takka alle som har kome med opplysningar om fuglens utbreiing og habitatvilkår. Ei fullstendig liste over informantar finst i Stenberg (2001). I tillegg har eg innhenta viktige data frå viltkartverket hos Fylkesmenn og kommunar. Eg er vidare takksam for at Geir Gaarder, Arne Heggland og Olav Hogstad har kome med nyttige kommentarar til manuskriptet. Arbeidet er finansiert av Direktoratet for Naturforvaltning, som eg hermed takkar for økonomisk støtte.

\section{REFERANSAR}

Andersen, B.E. 1988. Registrering av kvitryggspett $i$ Østfold. Perioden 1.10.87-1.11.88. Notat til Fylkesmannen i Østfold, miljøvernavdelingen.

Angelstam, P. \& Mikusinski, G. 1994. Woodpecker assemblages in natural and managed boreal and hemiboreal forest - a review. - Ann.Zool. Fenn. 31: 157-172.

Arvidsson, I. 2000. Lettisk vitrygg i Råadalen. - Hackspett-nytt 1-00: 3. Svenska Naturskyddsföreningen.

Aulén, G, 1986. Vitryggiga hackspettens Dendrocopos leucotos utbredningshistoria och förekomst $\mathrm{i}$ Sverige. - Vår Fågelvärld 45: 201-226.

Aulén, G. 1988. Ecology and distribution of the Whitebacked Woodpecker Dendrocopos leucotos in Sweden. Ph.D. thesis: Swedish University of Agricultural Sciences, Department of Wildlife Ecology, report No. 14, Uppsala.

Aulén, G., Ahlén, I., Carlson, A., Tjernberg, M. \& Eriksson, P. 1992. Vitryggig hackspett. Side 105-108 i: Ahlén, I. \& Tjernberg, M. (red.) Artfakta. Sveriges hotade och sällsynta ryggradsdjur 1992. Databanken för hotade arter, Sveriges lantbruksuniversitet, Uppsala.

Bengtson, R. 1993. Resultater fra hakkespettunders $\varnothing$ kelsen i Aust-Agder 1992. - Larus marinus 
22: $38-40$.

Bleckert, S. \& Petterson, R. 1997. Liv i skogen. En handledning i praktisk naturvård. Södra, Växjö.

Carlson, A. 1999. The effect of habitat loss on a deciduous forest specialist species: the White-backed Woodpecker (Dendrocopos leucotos). - Forest Ecology and Management 4898: 1-7.

Chapman, E. 1987. Fuglelivet på Voss før, no og i framtida. - Krompen 16: 4-20

Collett, R. 1864. Oversigt over Christiania Omegns ornithologiske Fauna. Christiania. Johan Dahl.

Collett, R, 1921. Norges Fugle, annet bind. Aschehoug \& Co.

Cramp, S. 1985. (red.) The Birds of the Western Palearctic, Vol. IV. Oxford University Press, Oxford.

Direktoratet for naturforvaltning 1999. Nasjonal rødliste for truete arter i Norge 1998. DNrapport 1999-3.

Edvardsen,E., Solbakken, K.A \& Myklebust, M. 1997. Kartlegging av hvitryggspett i Trøndelag 1997. NOF Rapportserie nr. 7-1997.

Edvardsen, E. Silsand, T.E., Solvang, R. \& Sørensen, K. 1999. Kartlegging av rødlistede spettearter $i$ Telemark 1998. Norsk Ornitologisk Forening, avdeling Telemark 1999.

Eriksson, P. \& Aulén, G. 1992. Àtgärdsprogram för vitryggig hackspett (Dendrocopos leucotos). Rapport til Naturvårdsvärket.

Fernandez, C. \& Azkona, P. 1996. Influence of forest structure on the density and distribution of the White-backed Woodpecker Dendrocopos leucotos and Black Woodpecker Dryocopus martius in Quinto Real (Spanish western Pyrenees). - Bird Study 43: 305-313.

Frølandshagen, R. 1996. Ornitologiske observasjoner i Østfold - nytt fra den lokale rapport- og sjeldenhetskomiteen (LRSK). - Natur $i$ Østfold 15: 5-21.

Fylkesmannen \& Fylkeskommunen i Buskerud 1996. Biologisk mangfold i Buskerud. Truede og sårbare arter og deres leveområder. Rødlister.

Fylkesmannen i Hordaland 1993. Skogen i Hordaland. Trykt hefte.

Gaarder, G, Hofton, T.H., Holtan, D., Stenberg, I. \& Heggland, A. 2004. Biologisk mangfold og vilt i Lomsdal-Visten. Supplerende unders $\varnothing$ kelser i 2004. - Miljøfaglig utredning, rapport 2004: 30.

Gjerde, I. 1993. Skogbruk og fauna på Vestlandet: Betydningen av treslagsskifte for forekomst og fordeling av skogshabitat. - Rapport fra Skogforsk 17/93.

Gjerde. I., Rolstad, J. \& Rinden, H. 1992. Hvitryggspetten på Østlandet: Hekkehabitat og bestandsutvikling sett i forhold til driftsendringer $i$ skogbruket. Rapport IV fra forskningsprogrammet «Skogøkologi og flersidig skogbruk».

Gjershaug, J.O., Thingstad, P.G, Eldøy, S.\& Byrkjeland, S. (red.). 1994. Norsk fugleatlas. Norsk Ornitologisk Forening, Klæbu. 551 s.

Glutz von Blotzheim, U.N. \& Bauer, K.M. 1980. Handbuch der Vögel Mitteleuropas, band 9. Akademische Verlagsgesellschaft, Wiesbaden.

Haftorn, S. 1994. Forord. I: Gjershaug, J.O., Thingstad, P.G, Eldøy, S.\& Byrkjeland, S. (red.). 1994. Norsk fugleatlas. Norsk Ornitologisk Forening, Klæbu.

Heggland, A. 1991. Prosjekt hvitryggspett-dvergspett Østlandet 1988-89. - Vestfold-Ornitologen 12: 21-29.

Heggland, A. 2000. Hvordan står det til med hvitryggspetten i Telemark? - Fugler i Telemark 1-2: $18-26$.

Heggland,A. 2004a. Hvitryggspett i Telemark: Resultat av inventeringer $\mathrm{i}$ Tinnsj $\varnothing-$ og Bandakområdet 2003 samt oppdatert bestandsstatus. - NOF-Telemark rapport 2004-1.

Heggland, A. 2004 b. Opprettelse og førstegangs inventering av faste analyseruter for bestandsovervåking av hvitryggspett i Aust-Agder. - Fugler i Aust-Agder Supplement 2004.

Hogstad, O. 1970. On the Ecology of the Three-toed Woodpecker Picoides tridactylus (L.) outside the breeding season. - Nytt. Mag. Zool. 18: 221-227.

Hogstad, O. \& Stenberg, I. 1997. Breeding success, nestling diet and parental care in the Whitebacked Woodpecker (Dendrocopos leucotos). - J. Orn. 138: 25-38.

Hågvar, S. 1991. Et variert fugleliv. S. 84-105 i: Berntsen, B. \& Hågvar, S. (red.). Norsk Urskog. Universitetsforlaget. Oslo.

Håland, A. 1985. Vestnorske skoger. Skogbruk, fugl og forvaltning. - Vår Fuglefauna 8: 239-254.

Håland, A. \& Toft, G.O. 1983. Hvitryggspettens forekomst og habitatvalg på Vestlandet. Vår Fuglefauna 6: 3-14.

Håland, A. \& Ugelvik, M. 1987. Utbredelse og bestandssituasjon hos hvitryggspett på Østlandet og i Trøndelag. - Vår Fuglefauna 10: 195-200.

Håland, A. \& Ugelvik, M. 1992. Hvitryggspettens $\varnothing$ kologi i relasjon til et flersidig skogbruk. I Solbraa, K. \& Grønvold, S. (red.) Skog$\varnothing$ kologi og flersidig skogbruk III. - Rapport fra Skogforsk 13/92.

Jensen, T. 1996. Biologisk mangfold i Drammen kommune. Drammen kommune, Kultursektoren. Naturforvaltningsseksjonen.

Kutschera, F. 1997. Spetteunders $\phi$ kingar i Ytre Namdal. Rapport til Fylkesmannen i NordTrøndelag.

Lehtiniemi, T. 2001. Suojelu-uutisiameiltä ja muualta. - Linnut 36: 14-15.

Lislevand, T. 1994. Resultater fra hakkespettunders $\varnothing \mathrm{k}-$ elsen i Aust-Agder 1993. - Larus marinus 
23: $13-16$.

Lislevand, T. 2000. Resultater fra spetteprosjektet i Aust-Agder i perioden 1997-1999. - Larus marinus 29: 36- 39.

Moe, B. 1991. Skogtypene på Vestlandet. S 29-37 i: Berntsen, B. \& Hågvar, S. (red.) Norsk Urskog. Universitetsforlaget.

Moen, A. 1998. Nasjonalatlas for Norge: Vegetasjon. Statens kartverk, Hønefoss.

Myklebust, M. 1996. Spetteunders $\varnothing$ kelser ved Vinjefjorden. NOF Rapportserie nr. 8-1996.

Olsson, G. 1998. Vitrygg i norra Bohuslän - en tillfällighet eller verklighet? - Fåglar på Västkusten 4: 217-221.

Opheim, J. \& Høitomt, G. 1990. Forekomst av hvitryggspett i Oppland fylke. - Fugler $i$ Oppland 11: $1-82$.

Opheim, J., Roang, J.K. \& Høitomt, G. 1998. Skjøtselsplan for et hekkeområde til hvitryggspett i S $\phi$ r-og Nord-Fron kommuner. Norsk Ornitologisk Forening avd. Oppland.

Rinden, H. 1988. Rapport fra undersøkelser om hvitryggspett $i$ Nordmarka og Østmarka. Rapport til miljøvernavdelinga i Oslo og Akershus.

Rinden, H. 1991. Hvitryggspetten på Østlandet - et offer for skogbruket. - Vår Fuglefauna 14: 51-56.

Scherzinger, W. 1982. Die Spechte im Nationalpark Bayerischer Wald. - Bayer. Staatsmin. ELF, Wiss. Schriften 9: 1-119.

Solbakken, K.A. 1999. Hvitryggspetten i Trøndelag - status fram til 1999. - Trøndersk Natur 26: 47-50.

Solbakken,K.A., Edvardsen,E. \& Myklebust, M. 1999. Kartlegging av hvitryggspett i Trøndelag 1998. NOF Rapportserie $n r .2-1999$.

Solbakken, K.A., Rudolfsen, G. \& Myklebust, M. 2001a. Kartlegging av hvitryggspett i Trøndelag 1999. NOF Rapportserie $n r$. 3-2001.

Solbakken, K.A., Rudolfsen, G. \& Myklebust, M. 2001b. Kartlegging av hvitryggspett $i$ Tr $\phi n-$ delag 2000. Manuskript.

Sollien, A., Nesholen, B. \& Fosseidengen, J.E. 1976. Fuglefaunaen i Grue. Kvalitativ og kvantitativ registrering av fuglefaunaen $i$ Grue kommune med tilstøtende områder, Hedmark fylke. Trykt rapport.

Spiridinov, J. \& Virkkala, R. 1997. The White-backed Woodpecker. S. 454-455 i: Hagemeijer, W.J.M. \& Blair, M. (red.): The EBCC Atlas of European Breeding Birds. Poyser, London.

Stenberg, I. 1996. Nest site selection in six woodpecker species. - Fauna norv. Ser. C, Cinclus 19: 21-38.

Stenberg, I. 2000. Kvitryggspettens populasjonsbiologi. Ungfuglanes spredning. Årsrapport 2000 til Direktoratet for Naturforvaltning.

Stenberg, I. 2001. Kvitryggspetten i Noreg - status fram til 2001. - NOF Rapportserie $n r$. 62001.

Stenberg, I. \& Carlson, A. 1998. Territory occupancy and population dynamics in a viable Whitebacked Woodpecker (Dendrocopos leucotos) population. I: Stenberg, I. 1998. Habitat selection, reproduction and survival in the White-backed Woodpecker Dendrocopos leucotos. Dr. scient avhandling, NTNU Trondheim.

Stenberg, I. \& Hogstad, O. 1992. Habitat use and density of breeding woodpeckers in the 1990's in Møre og Romsdal county, western Norway. - Fauna norv. Ser. C, Cinclus 15: 49-61.

Stenberg, I. \& Stokke, P.K. 2003. Kvitryggspettens habitatval i Noreg. - NOF Rapportserie $n r$. 2-2003.

Stighäll, K., Wilde,F. \& Westeberg, T. 2004.Lövskogar med höga naturvärden $i$ Värmland. Lämpliga miljöer för vitryggig hackspett. Projekt Vitryggig hackspett Naturskyddsföreningen i Värmland.

Stokke, P.K. 1993. Prosjekt hvitryggspett-Vest-Agder. Arbeidsrapport 1993. Bestandsregistreringer for Vest-Agder fylke. Norsk Ornitologisk Forening, Avdeling Vest-Agder

Strøm, H., Edvardsen, E. \& Myklebust, M. 1998. Status for truete arter i Hedmark. Virveldyr. Fylkesmannen i Hedmark, Miljфvernavdelingen, Rapport $n r .16 / 98$.

Tiainen, J, 1990. Distribution changes and present status of Dendrocopos leucotos in Finland. S. 21-27 I: Carlson, A. \& Aulén, G. (red.) Conservation and Management of Woodpecker Populations. Swedish University og Agricultural Sciences, department of Wildlife Ecoloy. Report No. 17, Uppsala.

Tomter, S. 1994. Skog 94. Statistikk over skogforhold og-ressurser $i$ Norge. Norsk Institutt for Jord- og Skogkartlegging, Ås.

Virkkala, R., Alanko, T., Laine. \& Tiainen, J. 1993. Population contraction of the White-backed Woodpecker (Dendrocopos leucotos) in Finland as a consequence of habitat alteration. - Biol. Conserv. 66: 47-53.

Voie, R. 2001. Hvitryggspett i Ullensvang 2000-2001. - Krompen 2: 113.

Wergeland Krog, O.M. 1997. Viltet i Eidsberg, Kartlegging av viktige viltområder. Forvaltningsplan for viltressursene. Eidsberg kommune og Fylkesmannen i Østfold. 